\title{
Saturation and comparative mapping of the genomic region harboring Hessian fly resistance gene $\mathrm{H} 26$ in wheat
}

\author{
Guo Tai Yu $\cdot$ Xiwen Cai $\cdot$ Marion O. Harris • \\ Yong Qiang Gu $\cdot$ Ming-Cheng Luo $\cdot$ Steven S. Xu
}

Received: 26 September 2008 / Accepted: 8 March 2009 / Published online: 26 March 2009

(C) The Author(s) 2009. This article is published with open access at Springerlink.com

\begin{abstract}
Resistance gene H26, derived from Aegilops tauschii Coss., is one of the most effective $R$ genes against the Hessian fly [Mayetiola destructor (Say)], an important pest of wheat (Triticum aestivum L.). Using a limited number of PCR-based molecular markers a previous study mapped $H 26$ to the wheat chromosomal deletion bin 3DL30.81-1.00. The objectives of this study were to saturate the chromosomal region harboring $\mathrm{H} 26$ with newly developed PCR-based markers and to investigate the collinearity of this wheat chromosomal region with rice (Oryza sativa L.) and Brachypodium distachyon genome. A population of
\end{abstract}

Mention of trade names or commercial products in this article is solely for the purpose of providing specific information and does not imply recommendation or endorsement by the U.S. Department of Agriculture.

Communicated by J. Snape.

G. T. Yu • M. O. Harris

Department of Entomology,

North Dakota State University, Fargo, ND 58105, USA

X. Cai

Department of Plant Sciences,

North Dakota State University, Fargo, ND 58105, USA

Y. Q. Gu

USDA-ARS, Western Regional Research Center,

Albany, CA 94710, USA

M.-C. Luo

Department of Plant Sciences,

University of California, Davis, CA 95616, USA

S. S. Xu $(\bowtie)$

USDA-ARS, Northern Crop Science Laboratory,

P.O. Box 5677, University Station, Fargo, ND 58105, USA

e-mail: steven.xu@ars.usda.gov
$96 \mathrm{~F}_{2}$ individuals segregating at the $H 26$ gene locus was used for saturation mapping. All wheat ESTs assigned to the deletion bin 3DL3-0.81-1.00 were used to design STS (sequence tagged site) primers. The wheat ESTs mapped near $H 26$ were further used to BLAST rice and B. distachyon genomic sequences for comparative mapping. To date, 26 newly developed STS markers have been mapped to the chromosomal region spanning the $H 26$ locus. Two of them were mapped $1.0 \mathrm{cM}$ away from the $H 26$ locus. Comparative analysis identified genomic regions on rice chromosome 1 and Brachypodium Super contig 13 which are collinear with the genomic region spanning the $H 26$ locus within the distal region of 3DL. The newly developed STS markers closely linked to $H 26$ will be useful for mappedbased cloning of $H 26$ and marker-assisted selection of this gene in wheat breeding. The results will also enhance understanding of this chromosomal region which contains several other Hessian fly resistance genes.

\section{Introduction}

Hessian fly [Mayetiola destructor (Say)] is one of the most destructive insects in common wheat (Triticum aestivum L.) and durum wheat (Triticum turgidum L. var. durum) in the world (Berzonsky et al. 2003). Larval attack of the seedling causes plant death or stunting of growth while larval attack of the plant during stem elongation causes broken stems and shriveled seeds. Both result in significant economic losses. Chemical control is rarely used because timing of application is difficult and few effective insecticides are available. The most common cultural control practices are to delay fall seeding and to destroy the volunteer wheat. Biological control with parasites provides little protection for the current crop. The use of resistant cultivars is the 
most effective and economical approach (Berzonsky et al. 2003).

To date, 32 Hessian fly resistance genes have been identified in common and durum wheat and their relatives, designated $H 1$ through $H 32$ (Williams et al. 2003; Liu et al. 2005; Sardesai et al. 2005; McIntosh et al. 2008). Deployment of some of the resistance genes has provided effective control of the insect in North America. However, wide use of resistant cultivars leads to the emergence of new virulent genotypes of Hessian fly (Gallun et al. 1961). Co-evolution of Hessian fly and its hosts, including wheat and its relatives, generates genetic variations of Hessian fly and then results in various biotypes (Kudagamage et al. 1990; Ratcliffe et al. 1994). One resistance gene usually confers resistance to one or a few biotypes of Hessian fly.

Sixteen biotypes of Hessian fly have been identified according to their virulence to four differentials, $H 3$ (in 'Monon'), H5 (in 'Magnum'), H6 (in 'Caldwell'), and H7H8 ('Seneca') (Ratcliffe and Hatchett 1997). The 16 biotypes are designated Great Plains (GP), and A through O. The biotype $\mathrm{L}$ is virulent to all four differentials, while GP is avirulent to all of them. However, more biotypes, including $v H 9$ and $v H 13$, have been found (Formusoh et al. 1996; Zantoko and Shukle 1997), and more will be found in future. Some of them may have overcome the resistance from these four genes or other resistant genes. Although $\mathrm{H} 9$ and $H 13$ confer resistance to the most virulent biotype $\mathrm{L}$ of the 16 biotypes, they do not confer resistance to the biotype $v H 9$ and $v H 13$, respectively. The complexity of the interaction between Hessian fly and resistance genes in wheat and its relatives, and variability of Hessian fly in the virulence necessitate the deployment of newly identified resistant genes.

The gene H26, derived from Ae. tauschii (Cox and Hatchett 1994), confers resistance to Hessian fly populations that are currently difficult or impossible to control with other available $H$ genes (Cox and Hatchett 1994; Wang et al. 2006; Xu et al. 2006). H26 is one of only two genes that are highly effective against a Hessian fly population recently detected in Oklahoma (Ming-Shun Chen, personal communication). However, $H 26$ has not been commercially deployed. $\mathrm{H} 26$ was previously assigned to chromosome 4D using monosomic analysis (Cox and Hatchett 1994). Recently, this gene was mapped to the deletion bin 3DL3-0.81-1.00 on chromosome 3D using molecular markers (Wang et al. 2006). Because fewer molecular markers have been assigned to this distal deletion bin on 3DL than the homologous regions on chromosomes 3A and 3B (Somers et al. 2004), H26 locus was only loosely mapped with a few SSR markers and closely linked PCR-based markers have not been identified.

Wheat EST (expressed sequence tag) sequences can be used to develop user-friendly molecular markers such as
STS (sequence tagged site) and SSR (simple sequence repeat) (Peng and Capitan 2005; Zhang et al. 2005; Perugini et al. 2008). There are 1,050,314 wheat ESTs available (http://www.ncbi.nlm.nih.gov/sites/entrez). A total of 16,000 of the ESTs were mapped to wheat deletion bins (Qi et al. 2004). These deletion-mapped ESTs are particularly useful for developing PCR-based DNA markers for saturation and fine mapping of a chromosomal interval harboring the genes of interest and gene cloning. So far, 120 wheat ESTs have been mapped to 3DL3-0.81-1.0 (http:// wheat.pw.usda.gov/cgi-bin/westsq1/map_locus.cgi) and they are excellent resource for developing new PCR-based markers for saturation mapping of the genes within this chromosomal interval.

In addition to wheat EST, genomic sequence information from model species, such as rice (Oryza sativa L.) whose genome has been sequenced, has been used for molecular mapping and gene isolation through comparative analysis in wheat (Liu and Anderson 2003; Distelfeld et al. 2004; Francki et al. 2004). However, due to the many disruptions in collinearity between rice and the genomes of wheat and barley, Brachypodium distachyon has been proposed as another model species of cereals. The bacterial artificial chromosome (BAC) libraries (Foote et al. 2004; Huo et al. 2006, 2008; Hasterok et al. 2006), ESTs (Vogel et al. 2006), and partial assembled genomic sequences have become available in $B$. distachyon. Limited data suggested that Brachypodium is likely more closely related to wheat than rice (Vogel et al. 2006; Bossolini et al. 2007). Thus, the genomic sequences and ESTs of Brachypodium could be another invaluable resource for molecular mapping and gene cloning in wheat.

The objectives of this study were to saturate the chromosomal region harboring the $H 26$ locus using newly developed PCR-based STS (sequence tagged site) markers, which will facilitate not only deploying the $H 26$ gene in wheat cultivars but also the genomic study of this chromosomal interval; and to determine the collinearity of this wheat genomic region with rice and Brachypodium genome.

\section{Materials and methods}

Plant materials and STS marker analysis

The mapping population of $96 \mathrm{~F}_{2}$ individuals derived from the cross between the resistant synthetic hexaploid wheat (SHW) line SW8 (Langdon/Ae. tauschii Clae 25) and the susceptible SHW line SW11 (Langdon/Ae. tauschii H-80114-1) (Wang et al. 2006) was used for saturation mapping in the present study. DNA was extracted from the preserved $\left(-80^{\circ} \mathrm{C}\right)$ young leaf tissues of the population as described 
by Dellaporta et al. (1983). One hundred and twenty wheat ESTs, assigned to the chromosomal bin 3DL3-0.81-1.0 where $H 26$ resides (http://wheat.pw.usda.gov/cgi-bin/westsql/ map_locus.cgi), were used to design primers with the computer program Primer3 (http://frodo.wi.mit.edu/cgi-bin/ primer3/primer3_www.cgi) (Rozen and Skaletsky 2000) to detect STS marker loci near the $H 26$ locus. The primers of the STS markers mapped to this chromosomal region are listed in Table 1. Four SSR markers (Xcfd223, Xgwm3, $X c f d 211$, and Xbarc71) that linked to H26 locus (Wang et al. 2006) were used as the anchors in this study and their primer sequences were obtained from the GrainGenes Database (http://wheat.pw.usda.gov/GG2/index.shtml).

Bulked segregant analysis was performed to identify marker loci closely linked to H26. Two bulks of DNA were prepared by pooling equal amounts of DNA from eight homozygous resistant and eight homozygous susceptible $\mathrm{F}_{2}$ individuals, respectively. The STSs were amplified at optimized PCR conditions. The annealing temperature for PCR was determined based on the melting temperature $\left(T_{\mathrm{m}}\right)$ of the primer pair. It was calculated by subtracting 5 from the $T_{\mathrm{m}}$ of the primer with lower $T_{\mathrm{m}}$ value (Innis and Gelfand 1990) and was adjusted based on the relative intensity of target band among the all amplified ones for a primer pair (Table 1). The SSRs were amplified as described by Röder et al. (1998). PCR products were separated on 6\% non-denaturing polyacrylamide gels in $0.5 \mathrm{XTBE}$ buffer at $120 \mathrm{~W}$ for $1 \mathrm{~h}$. The gels were scanned with a Typhoon 9410 variable mode imager (Molecular Dynamics, Ithaca, NY, USA) after staining with GelRed (Sigma, St. Louis, MO, USA).

Linkage of molecular markers with $H 26$ in the mapping population was analyzed using MAPMAKER 2.0 (Lander et al. 1987) for Macintosh at LOD 6.0 with the Kosambi mapping function (Kosambi 1944).

\section{Comparative analysis}

For comparative analysis with the rice or Brachypodium genome, tentative consensus (TC) or EST sequences were subjected to BLASTn searches of the rice genomic sequences in the Gramene database (Ware et al. 2002; http:// www.gramene.org/Multi/blastview) or to search of Brachypodium super contigs (http://www.brachypodium.org). For BLASTn searches, the threshold limits for significant hits were at least $80 \%$ nucleotide identity for at least 60 bases. We set e-value $<\mathrm{e}^{-7}$ in order to include maximum number of EST or TC hits with lowest e-value. When several significant hits were found, only the best hit was adopted.

To search wheat TCs corresponding to rice PAC AP003238, which is hit by the EST of the closet STS marker (Xrwgs 12)-H26, the sequence of the rice PAC was subjected to BLASTn (Altschul et al. 1997) against wheat
EST clusters (TIGR gene indices). A significant match for a TC was declared on the basis of e-value of $<\mathrm{e}^{-31}$ which was used to reduce the similarity among the significant TCs. The TC sequences were obtained from the Annotator Search of DFCI (http://compbio.dfci.harvard.edu/tgi/cgibin/tgi/tc_ann.pl?gudb=wheat). The TC sequences were then subjected to tBLASTx (Ware et al. 2002; http://blast. ncbi.nlm.nih.gov/Blast.cgi?PAGE=Translations\&PROGR $\mathrm{AM}=$ tblastx \&BLAST_PROGRAMS=tblastx \&PAGE_ TYPE=BlastSearch\&SHOW_DEFAULTS=on\&LINK_ LOC=blasthome) searches of the NCBI nucleotide collection (nr/nt) to identify the putative corresponding protein. A significant match for a protein was declared on the basis of a minimum $80 \%$ amino acid identity for at least 50 amino acid residues of the protein sequence and an e-value of $<\mathrm{e}^{-7}$. The hit with the lowest e-value was considered the putative protein of a TC when several matches were found. The known genes within the rice genomic region AP003238 were obtained through TIGR v5 in Gramene (http://www. gramene.org/Oryza_sativa_japonica/index.html).

\section{Results}

More than 500 STS primer pairs were designed based on the sequences of the 120 wheat ESTs assigned to the deletion bin 3DL3-0.81-1.00. These primer pairs were then tested for polymorphisms between the two parents of the mapping population. Fifty-one pairs of primers were found to amplify polymorphic bands between two parents (Fig. 1). Bulked segregant analysis identified 24 STS co-dominant markers linked to $H 26$ and they were mapped to the deletion bin 3DL3-0.81-1.00 (Table 1; Fig. 1). Thus, $20 \%$ of the ESTs within this chromosomal interval were converted to STS markers.

In order to exploit the genomic sequences of the model species, rice and Brachypodium, the collinearities of the wheat genomic region harboring the $H 26$ locus with rice and Brachypodium genomes were studied to develop additional markers for wheat. We designed 48 and 46 pairs of STS primers from the sequences of the rice and Brachypodium genomic regions which are collinear with the wheat genomic region harboring $H 26$, respectively. One STS marker (Xrwgs 17) developed from rice and one (Xrwgs10) from Brachypodium genomic sequences were mapped to the $H 26$ region (Table 2). A total of 26 STS markers were mapped to the distal region of $3 \mathrm{DL}$ that resides within the deletion bin 3DL3-0.81-1.00 (Fig. 2).

The genetic map of partial 3DL, which spans a genetic distance of $42.5 \mathrm{cM}$ with 30 molecular markers, was constructed in the population. This linkage map represents an average density of one marker per $1.4 \mathrm{cM}$. All markers were mapped at $\mathrm{LOD} \geq 6.0$. Two co-segregating STS 
Table 1 STS markers developed from wheat ESTs, rice genomic sequences, and Brachypodium genomic sequences

\begin{tabular}{|c|c|c|c|}
\hline STS marker & PCR primers & $\begin{array}{l}\text { Annealing } \\
\text { temperature }\left({ }^{\circ} \mathrm{C}\right)^{\mathrm{a}}\end{array}$ & $\begin{array}{l}\text { EST accession/ } \\
\text { genomic group }\end{array}$ \\
\hline Xrwgs 1 & $\begin{array}{l}\text { GCTGTCGCACAAGCAATAAA } \\
\text { CGGCCCGTACAGAAGTGTAT }\end{array}$ & 55 & BE404125 \\
\hline Xrwgs2 & $\begin{array}{l}\text { TTTTGAACAACAATTGATCT } \\
\text { ATGAGCCGGTGGTG }\end{array}$ & 48 & BE590549 \\
\hline Xrwgs3 & $\begin{array}{l}\text { TGACTTATCCCGAGTGACCAG } \\
\text { TGCTATCTTTGCTTGTGCTACAG }\end{array}$ & 55 & BF485004 \\
\hline Xrwgs4 & $\begin{array}{l}\text { ATGGCTACCCACTGGACAAG } \\
\text { CTCTGATTTCGCCAGGAAAG }\end{array}$ & 55 & BE443397 \\
\hline Xrwgs5 & $\begin{array}{l}\text { GTTCTCGGCATCAATCACCT } \\
\text { AGAGCTATGCCCATGGTGAC }\end{array}$ & 55 & BG262734 \\
\hline Xrwgs6 & $\begin{array}{l}\text { AAGGACGACGTCAAGCTCAT } \\
\text { AGGATTGGAACAACGTCCAG }\end{array}$ & 55 & BE591925 \\
\hline Xrwgs 7 & $\begin{array}{l}\text { CCGAGGACGTCGAGAAAAAC } \\
\text { CCGAGGACGTCGAGAAAAAC }\end{array}$ & 57 & BE444335 \\
\hline Xrwgs8 & $\begin{array}{l}\text { TGCTCCCAAAGCTCTCATCT } \\
\text { TGGAGCTTTGAGCAGGTTTT }\end{array}$ & 55 & BE498661 \\
\hline Xrwgs9 & $\begin{array}{l}\text { CCATTTGGCACAATGACTTG } \\
\text { GCTGTGGAAGCATCTTGTGA }\end{array}$ & 55 & BE405038 \\
\hline Xrwgs10 & $\begin{array}{l}\text { CCTAACTGAGGTCCCACCAA } \\
\text { GCAAAGGACTTGATGCCTGT }\end{array}$ & 55 & $\begin{array}{l}\text { Brachypodium } \\
\quad \text { Super contig } 13\end{array}$ \\
\hline Xrwgs11 & $\begin{array}{l}\text { GGAGAGTCGCAGGATCCA } \\
\text { TCTCTGCCCAGTCCAACTTT }\end{array}$ & 55 & BE403428 \\
\hline Xrwgs 12 & $\begin{array}{l}\text { CGTATCGGCGACAAGGTAAT } \\
\text { ACTGGAAGAAGCCCCAGTCT }\end{array}$ & 55 & BE426418 \\
\hline Xrwgs 13 & $\begin{array}{l}\text { ACAACCAGGGACTGATCGAC } \\
\text { CACCACCAGGAACAGGAAGT }\end{array}$ & 55 & BM138635 \\
\hline Xrwgs 14 & $\begin{array}{l}\text { CATGACGGAGAGAGATGCAA } \\
\text { CAACTCCCAGTTTGCTGACA }\end{array}$ & 55 & PSR1205 \\
\hline Xrwgs 15 & $\begin{array}{l}\text { GAGGCCATCAAGTCCAAGTT } \\
\text { TGGGTTCGTGAAGAAAAAGC }\end{array}$ & 55 & BE426763 \\
\hline Xrwgs16 & $\begin{array}{l}\text { ATGCATGCTAATTAGCTAGT } \\
\text { TGTTCCCTTGTACAAGTAGA }\end{array}$ & 47 & BG608151 \\
\hline Xrwgs17 & $\begin{array}{l}\text { TCTCTGAGGGGAAGCAAGAA } \\
\text { СТССТCCCATTCCCCATATC }\end{array}$ & 55 & $\begin{array}{l}\text { Rice chromosome } \\
1 \mathrm{~L} \text { distal end }\end{array}$ \\
\hline Xrwgs 18 & $\begin{array}{l}\text { TGAAGCAATCAGCAATTGGA } \\
\text { CCTCGTAACTGAAGCCTGGA }\end{array}$ & 55 & BE490274 \\
\hline Xrwgs19 & $\begin{array}{l}\text { TTGGTAATTTTTCGGCTTGC } \\
\text { CTGTTTACGGCAATGGGATT }\end{array}$ & 55 & BE444864 \\
\hline Xrwgs 20 & $\begin{array}{l}\text { ACCGACATCACCCATGTCTT } \\
\text { CTGCAATTGAAAGCCTCGTT }\end{array}$ & 55 & BE605103 \\
\hline Xrwgs21 & $\begin{array}{l}\text { GGAGAAGCATCACAAGCACA } \\
\text { TCCTTCATCTTGTGCGACCT }\end{array}$ & 55 & BE446756 \\
\hline Xrwgs22 & $\begin{array}{l}\text { ACAATGGCTAGCTATGGAGATGT } \\
\text { CGTTCACGCACGAGTAAAAC }\end{array}$ & 55 & BE444579 \\
\hline Xrwgs23 & $\begin{array}{l}\text { CTCAAGGACCTGCTGGAGAC } \\
\text { ATCTAGAGGCGCGACAAAAA }\end{array}$ & 55 & BE489841 \\
\hline
\end{tabular}


Table 1 continued

\begin{tabular}{llll}
\hline STS marker & PCR primers & $\begin{array}{l}\text { Annealing } \\
\text { temperature }\left({ }^{\circ} \mathrm{C}\right)^{\mathrm{a}}\end{array}$ & $\begin{array}{l}\text { EST accession/ } \\
\text { genomic group }\end{array}$ \\
\hline Xrwgs24 & $\begin{array}{l}\text { TGATGGATGAGTACTATGTTGGTGA } \\
\text { CGGTGACGCTGGTACAAAAT } \\
\text { Xrwgs25 }\end{array}$ & 56 & BE637789 \\
& $\begin{array}{l}\text { TCGACTTCAGGAGCCACTTT } \\
\text { CACGTTCAGGAACTGCTTCA }\end{array}$ & 55 & BM7927 \\
& TGAACGGTATACAAGTGCGAGT 6591864
\end{tabular}

${ }^{a}$ Annealing temperature was determined based on melting temperature $\left(T_{\mathrm{m}}\right)$ of a primer pair (Innis and Gelfand 1990) and the relative intensity of the target band amplified by the primer pair

${ }^{b}$ Wheat EST accessions were obtained from website: http://wheat.pw.usda.gov/cgi-bin/westsql/map_locus.cgi, accessed 2 Jan 2009

Fig. 1 Four examples of STS primers that generated polymorphic bands as co-dominant markers between two parents. P1 and $\mathrm{P} 2$ are the parents SW8 and SW11, S and R are homozygous susceptible and resistant $\mathrm{F}_{2}$ plants, respectively

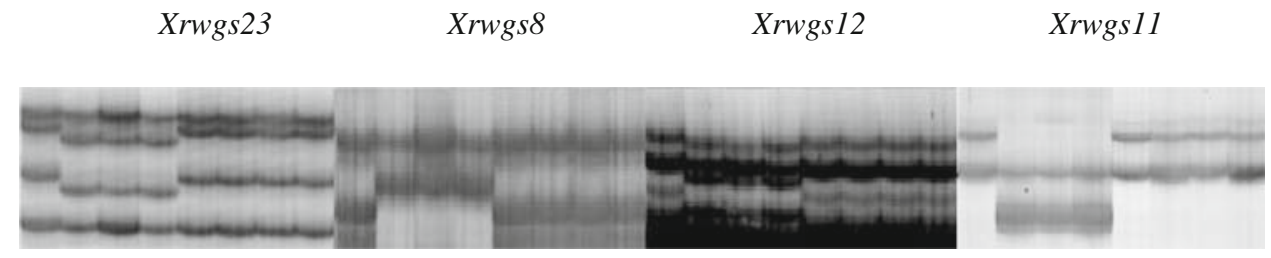

P1 P2 S S R R R R P1 P2 S S R R R R P1 P2 S S R R R R P1 P2 S S R R R R markers, Xrwgs11 and Xrwgs12, have distances of $1 \mathrm{cM}$ from the $H 26$ locus. Another marker, Xrwgs 10 , is $3.2 \mathrm{cM}$ proximal to H26. Several STS markers, such as Xrwgs4, Xrwgs5, and Xrwgs6, were co-segregating in the mapping population (Fig. 2). However, they were developed from different ESTs or TCs.

To evaluate the local collinearity of the deletion bin 3DL3-0.81-1.00 with rice genome we blasted the rice genome using 24 ESTs or corresponding TCs from which the mapped STS markers were developed. Fifteen of the ESTs or TCs hit the distal region of rice chromosome 1, two hit chromosome 3, one hit chromosomes 8 and 10 , whereas five of the ESTs or TCs did not hit any rice genomic region under the significance threshold (Table 2). In general, there is good collinearity between the distal region of wheat 3DL and rice chromosome 1 . However, wheat EST BE426418 detected a locus close to the one that EST BE444864 corresponded to in rice (Fig. 3).

To determine the collinearity between the deletion bin 3DL3-0.81-1.00 and Brachypodium genomic region(s), the 24 mapped ESTs or corresponding TCs were used as queries to BLAST against Brachypodium genomic sequences. Fifteen of the ESTs or corresponding TCs hit the Brachypodium Super contig 13 (Table 2). Two TCs (TC265775 and TC252434) hit the Super contig 3 and one (TC276760) hit the Super contig 2. Six of them did not hit any Brachypodium contig under the significance threshold (at least 60 bases, and an e-value of $<\mathrm{e}^{-7}$ ) (Table 2). Fourteen of the 15 ESTs or TCs and the marker Xrwgs 10 are perfectly collin- ear between the distal region of $42.5 \mathrm{cM}$ (from marker Xrwgs1-Xrwgs26) of wheat chromosome 3DL and Super13 contig of Brachypodium genome, but, as was seen in rice, EST BE426418 identified a locus close to the one that EST BE444864 corresponded to (Fig. 3).

Since the STS marker Xrgws 12 derived from the EST BE426418 is $1 \mathrm{cM}$ from $H 26$ locus we blasted rice genomic sequences using BE426418 as a query (Table 3). The rice genomic sequence collinear with BE426418 is derived from the PAC AP003238. Within this rice genomic region 14 known genes were found (Table 3). Among them are genes for a membrane attach component, lipase, DNA binding, Leucine rich repeat (LRR), and fungal lignin peroxidase (Table 3).

To search for putative genes corresponding to the wheat TCs that were hit by the rice PAC AP003238 we blasted the wheat EST clusters with AP003238 (Table 4). Twelve significant TCs were identified. Using tBLASTx, we blasted the NCBI nucleotide collection (nr/nt) with these TC sequences and obtained eleven predicted proteins, including one integral membrane protein-2B and one similar to ETS domain (DNA-binding domain). However, functions for rest of the predicted proteins are unknown (Table 4).

\section{Discussion}

Hessian fly resistance gene $H 26$ was previously mapped to the 3DL distal region 3DL3-0.81-1 (Wang et al. 2006). Because this chromosomal interval has fewer PCR-based 
Table 2 STS markers, their corresponding ESTs and TCs, and similarity to the Brachypodium and rice genomic sequences

\begin{tabular}{|c|c|c|c|c|c|c|}
\hline \multirow[t]{2}{*}{ Marker } & \multirow{2}{*}{$\begin{array}{l}\text { EST accession/ } \\
\text { genomic region }\end{array}$} & \multirow[t]{2}{*}{$\mathrm{TC}$ accession } & \multicolumn{2}{|c|}{ Brachypodium } & \multicolumn{2}{|l|}{ Rice } \\
\hline & & & Contig $^{\mathrm{a}}$ & e-Value & Chromosome & e-Value \\
\hline Xrwgsl & BE404125 & TC236858 & Super 13 & $2.0 \mathrm{e}-77$ & 1 & $5.9 \mathrm{e}-123$ \\
\hline Xrwgs 2 & BE590549 & TC265775 & Super 3 & $8.0 \mathrm{e}-10$ & $\mathrm{NS}^{\mathrm{b}}$ & \\
\hline Xrwgs3 & BF485004 & TC263479 & Super 13 & $1.0 \mathrm{e}-130$ & 1 & $2.4 \mathrm{e}-291$ \\
\hline Xrwgs4 & BE443397 & TC252434 & Super 3 & $4.0 e-96$ & 10 & $1.7 \mathrm{e}-168$ \\
\hline Xrwgs5 & BG262734 & $\mathrm{NA}^{\mathrm{c}}$ & Super 13 & $7.0 e-37$ & 1 & $8.8 \mathrm{e}-42$ \\
\hline Xrwgs6 & BE591925 & TC272750 & Super 13 & $4.0 \mathrm{e}-27$ & 1 & $4.9 \mathrm{e}-34$ \\
\hline Xrwgs 7 & BE444335 & TC241376 & Super 13 & $2.0 \mathrm{e}-16$ & 1 & $1.5 \mathrm{e}-08$ \\
\hline Xrwgs8 & BE498661 & TC253823 & NS & & NS & \\
\hline Xrwgs9 & BE405038 & NA & NS & & NS & \\
\hline Xrwgs 10 & $\begin{array}{l}\text { Brachypodium } \\
\quad \text { Super contig } 13\end{array}$ & NA & & & & \\
\hline Xrwgs11 & BE403428 & TC255189 & NS & & 3 & $5.9 \mathrm{e}-29$ \\
\hline Xrwgs12 & BE426418 & NA & Super 13 & $9.0 \mathrm{e}-14$ & 1 & $2.0 \mathrm{e}-13$ \\
\hline Xrwgs 13 & BM138635 & TC247552 & Super 13 & $9.0 \mathrm{e}-91$ & 1 & $1.7 \mathrm{e}-133$ \\
\hline Xrwgs14 & PSR1205 & NA & NS & & NS & \\
\hline Xrwgs 15 & BE426763 & TC270760 & Super 2 & $1.0 \mathrm{e}-33$ & 1 & $3.1 e-82$ \\
\hline Xrwgs16 & BG608151 & TC257542 & NS & & 8 & $1.5 \mathrm{e}-10$ \\
\hline Xrwgs17 & Rice chromosome $1 \mathrm{~L}$ & NA & & & & \\
\hline Xrwgs18 & BE490274 & TC238164 & Super 13 & $2.0 \mathrm{e}-38$ & 1 & $1.3 e-32$ \\
\hline Xrwgs19 & BE444864 & NA & Super 13 & $2.0 \mathrm{e}-40$ & 1 & $8.0 \mathrm{e}-90$ \\
\hline Xrwgs20 & BE605103 & TC251323 & NS & & 3 & $2.4 \mathrm{e}-227$ \\
\hline Xrwgs21 & BE446756 & TC244950 & Super 13 & $2.0 \mathrm{e}-28$ & 1 & $2.0 \mathrm{e}-59$ \\
\hline Xrwgs22 & BE444579 & TC268986 & Super 13 & $2.0 \mathrm{e}-32$ & 1 & $5.7 e-43$ \\
\hline Xrwgs23 & BE489841 & TC233450 & Super 13 & $5.0 \mathrm{e}-58$ & 1 & $4.2 \mathrm{e}-223$ \\
\hline Xrwgs24 & BE637789 & TC233150 & Super 13 & $8.0 \mathrm{e}-76$ & 1 & $5.0 \mathrm{e}-84$ \\
\hline Xrwgs25 & BM137927 & NA & Super 13 & $4.0 \mathrm{e}-60$ & 1 & $1.7 e-50$ \\
\hline Xrwgs26 & BE591864 & NA & Super 13 & $1.0 \mathrm{e}-20$ & NS & \\
\hline
\end{tabular}

a These sequence data were produced by the US Department of Energy Joint Genome Institute http://www.jgi.doe.gov/ (with consent of the Brachypodium Genome Sequencing Project co-directors Drs. John Vogel, Michael Bevan, and David Garvin)

${ }^{b}$ Not significant based on the criteria (at least 60 bases, and an e-value of $<\mathrm{e}^{-7}$ )

${ }^{c}$ A TC was not available

markers than other regions according to the consensus genetic map (Somers et al. 2004) the H26 locus was roughly mapped with only eight SSR markers and one TRAP marker in the previous mapping endeavor (Wang et al. 2006). The molecular markers tightly linked to $H 26$ have not been identified previously. Through saturation mapping in the present study we successfully developed 26 new STS markers and mapped them onto this region. Two of the STS markers (Xrwgs11 and Xrwgs12) are $1 \mathrm{cM}$ away from $H 26$ locus. Another marker, Xrwgs 10, is $3.2 \mathrm{cM}$ proximal to $H 26$. Since $H 26$ conditions resistance to multiple biotypes of Hessian fly, including $v H 13$ (Cox and Hatchett 1994; Wang et al. 2006; Xu et al. 2006), these three STS markers will be useful for markerassisted selection in wheat breeding and germplasm development.
In addition to $H 26$, several other economically and genetically important genes reside within the 3DL distal region 3DL3-0.81-1, including $H 24$ (Ma et al. 1993) and H32 (Sardesai et al. 2005) for resistance to Hessian fly, Lr24 for resistance to leaf rust (Puccinia triticina Erikss) (Boyko et al. 1999), $R l$ for red kernel color (Nelson et al. 1995), Chl2 for hybrid chlorosis (Koba and Tsunewaki 1978; Erayman et al. 2004), and the genes for Esterase-5 (Devos and Gale 1993) and $\beta$-(1-3)-Glucanase (Li et al. 2001). Thus, the 26 newly developed STS markers in our study will facilitate the genetic study of a number of important traits or genes in this region.

The homoeologous group 3 of wheat is considered to be collinear to chromosome 1 of rice (Ahn et al. 1993; Kurata et al. 1994; Munkvold et al. 2004; Dilbirligi et al. 2006), but detailed studies on the microcollinearity particularly 
Fig. 2 Comparative analysis of the saturated genetic map of 3DL terminal region, the consensus SSR genetic map of 3D, and 3D deletion map. Marker loci are listed to the right and centiMorgan (cM) distances to the left. Dashed lines link the same loci in the three maps. a Saturated genetic map of $H 26$ with 26 new STS loci (Xrwgs 1Xrwgs26). b The consensus SSR map of 3D (Somers et al. 2004) showing gaps in the region. c Deletion map of 3D (Sourdille et al. 2004), indicating the chromosomal bin (shaded terminal region on the long arm) harboring Hessian fly resistance genes $H 26, H 32$, and H24. The fraction-length of the chromosomal bins (within parentheses), the breakpoints, and the centromere of Chinese Spring chromosome $3 \mathrm{D}$ are shown to the right
$\mathrm{cM}$

Marker

(1)

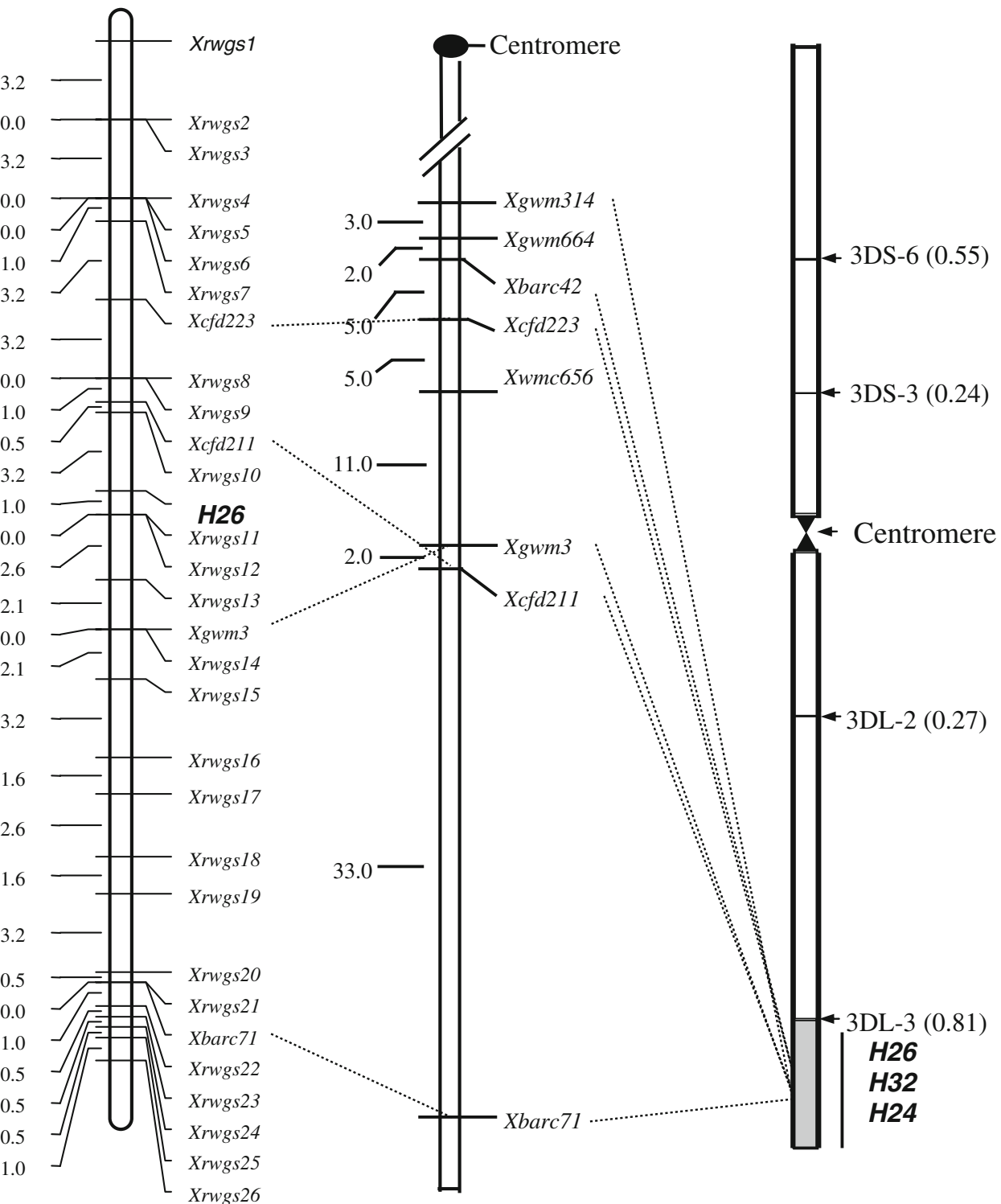

b

c

Marker

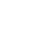




\section{Wheat 3DL Genetic Map}

Rice chromosome 1

cM, EST/Marker bp

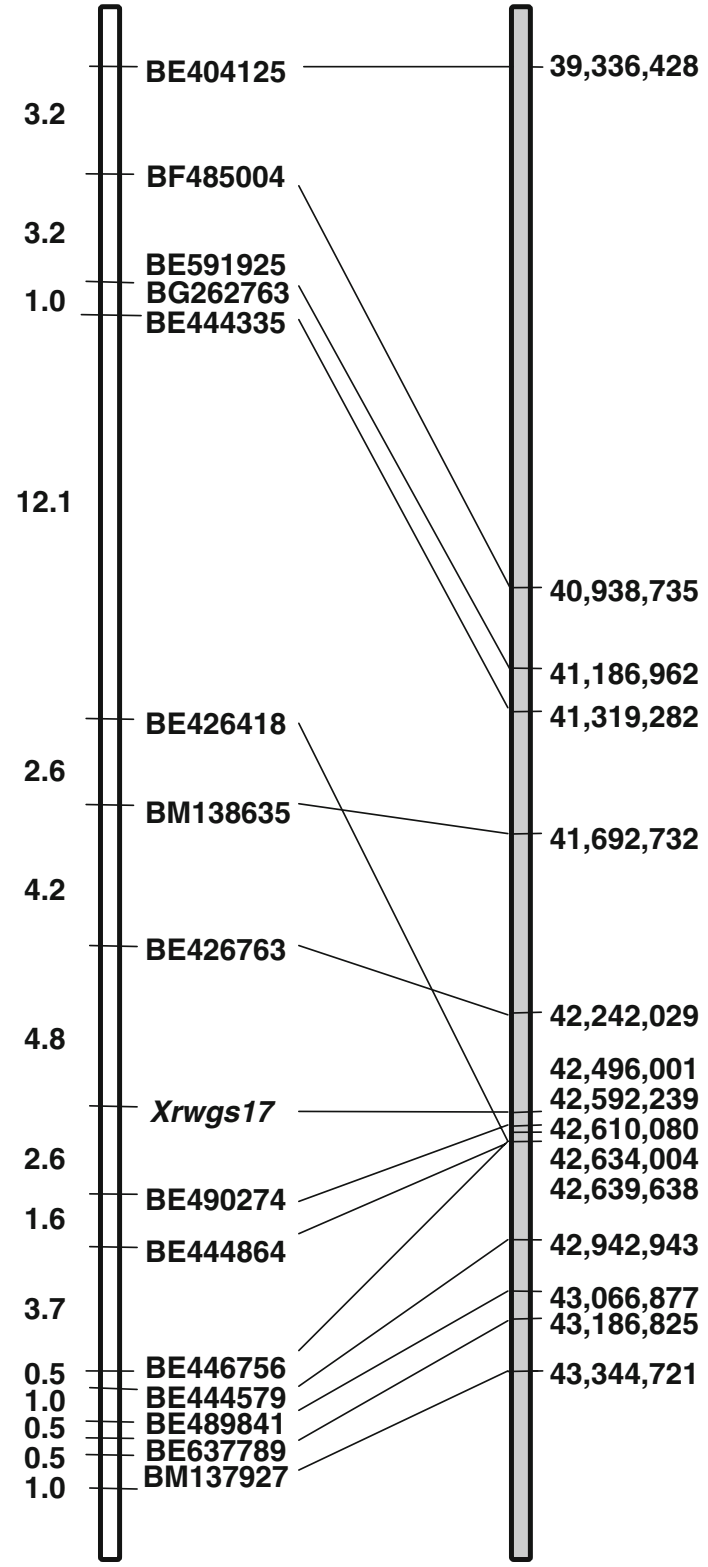

Fig. 3 Collinearity of the $H 26$ region of wheat (left) with corresponding genomic region of rice chromosome 1 (right). Physical locations corresponding to the EST markers on the genetic map of 3DL are indicated as base pairs on the genomic region of rice. Genetic distances between the markers were indicated as $\mathrm{cM}$ to the left of the genetic map. The STS marker Xrwgs 17 was developed directly from the rice genomic sequence

Due to the limited degree of collinearity observed in wheat-rice comparative studies, B. distachyon has been proposed as a new model grass to study genomics of largegenome cereals (Draper et al. 2001). However, little is known about the collinearity between wheat and Brachypo- dium at the chromosome level. In the comparative mapping of Lr34 orthologous regions (Bossolini et al. 2007), six of 11 wheat markers detected the collinearity between Brachypodium and wheat chromosome 7A, and six of 11 markers revealed the collinearity between Brachypodium and wheat chromosome 7D. The results from our study revealed that 15 of $24(63 \%)$ wheat ESTs evaluated had similar sequences as rice chromosome 1 . Fourteen of the 15 ESTs and one marker are collinear between the distal region of wheat 3DL and Brachypodium Super contig 13 (Table 2). This points to the utility of $B$. distachyon as a model for the understanding of the large and complex genomes of wheat.

On the other hand, the collinearity between wheat 3DL30.81-1.00 and Brachypodium Super contig 13 is not perfect. The discrepancies between wheat 3DL3-0.81-1.00 and Brachypodium Super contig 13 limit the development of STS markers for wheat chromosome 3D from the genomic sequences of the Brachypodium Super contig 13 based on the collinearity. We designed 46 pairs of STS primers with Brachypodium Super contig 13 sequences based on the collinearity, but only one was mapped to wheat chromosome 3D (Table 2; Fig. 2). Therefore, as seen with rice, cautions need to be taken when employing the Brachypodium genomic sequence for molecular mapping and gene cloning in wheat.

Brachypodium was reported to be more closely related to wheat than to rice (Vogel et al. 2006; Bossolini et al. 2007). The genomic regions of Brachypodium and rice corresponding to the wheat 3DL3-0.81-1.00 were found to be similar instead in this study. Both Brachypodium and rice had $63 \%$ of evaluated ESTs collinear with wheat (Table 2). The wheat EST BE426418 detected a locus close to the ones that EST BE444864 corresponded to in both rice and Brachypodium (Fig. 3). These results indicate complexity of the collinearity of wheat genomes with Brachypodium genome. Therefore, local comparative mapping is suggested before using Brachypodium genomic sequences for fine mapping or gene cloning in wheat.

The majority of the cloned resistance genes, including those for disease and insect resistance, encode proteins with a nucleotide-binding site (NBS) domain and a LRR domain (Hammond-Kosack and Jones 1997). NBS domains have been shown to bind and hydrolyze ATP in plants and animals, and ATP binding appears to be essential for signal transduction. The LRR domain is a key determinant of protein-protein interactions (Ellis et al. 2000). For examples, the Xanthomosnas resistance gene, $\mathrm{Xal}$, in rice (Yoshimura et al. 1998) and the nematode resistance gene, Cre3, in wheat (Lagudah et al. 1997) have been shown to be NBSLRR-like genes. NBS-LRR-like genes can be viable candidates for genes conditioning resistance to pest. In the present study, three genes with DNA binding, or ATP binding, or LRR were found within the rice PAC AP003238. Since the 
Table 3 Genes within the rice PAC AP003238

\begin{tabular}{|c|c|c|}
\hline Gene & Description & InterPro \\
\hline NP_001045455.1 & $\begin{array}{l}\text { MAC/Perforin domain containing } \\
\text { protein, expressed }\end{array}$ & $\begin{array}{l}\text { Membrane attack complex component/ } \\
\text { perforin/complement C9 }\end{array}$ \\
\hline NP_001045456.1 & Expressed protein & Lipase, active site \\
\hline NP_001045457.1 & MUTL protein homolog 1, putative, expressed & $\begin{array}{l}\text { DNA mismatch repair protein/ } \\
\text { ATP-binding region, ATPase-like }\end{array}$ \\
\hline NP_001045458.1 & $\begin{array}{l}\text { Serine/arginine repetitive matrix protein } 1 \text {, } \\
\text { putative, expressed }\end{array}$ & $\begin{array}{l}\text { Pistil-specific extensin-like protein/ } \\
\text { RNA recognition motif, RNP-1/HMG-I } \\
\text { and HMG-Y, DNA-binding }\end{array}$ \\
\hline NP_001045459.1 & Abscisic stress ripening protein 1, putative, expressed & ABA/WDS-induced protein \\
\hline NP_001045460.1 & Abscisic stress ripening protein 2, putative, expressed & ABA/WDS-induced protein \\
\hline Q5JN43_ORYSJ & $\begin{array}{l}\text { Pentatricopeptide repeat protein PPR1106-17, } \\
\text { putative, expressed }\end{array}$ & Pentatricopeptide repeat \\
\hline NP_001045461.1 & $\begin{array}{l}\text { Phosphatidylserine decarboxylase, putative, } \\
\text { expressed }\end{array}$ & $\begin{array}{l}\text { Phosphatidylserine decarboxylase-related/C2 } \\
\text { calcium/lipid-binding region, CaLB/Calcium-binding } \\
\text { EF-hand/Phosphatidylserine decarboxylase }\end{array}$ \\
\hline NP_001045462.1 & Expressed protein & $\begin{array}{l}\text { Histone } \mathrm{H} 5 / \text { Pollen allergen Poa pIX/Phl pVI, } \\
\text { C-terminal/Antifreeze protein, type I }\end{array}$ \\
\hline NP_001045463.1 & Expressed protein & \\
\hline NP_001045464.1 & Expressed protein & $\begin{array}{l}\text { Protein of unknown function/Glycyl-tRNA } \\
\text { synthetase, alpha2 dimer }\end{array}$ \\
\hline NP_001045465.1 & $\begin{array}{l}\text { tRNA uridine 5-carboxymethylaminomethyl } \\
\text { modification enzyme gidA, putative, expressed }\end{array}$ & $\begin{array}{l}\text { FAD-dependent pyridine nucleotide-disulfide } \\
\text { oxidoreductase/Glucose-inhibited division protein/ } \\
\text { Fumarate reductase/succinate dehydrogenase } \\
\text { flavoprotein, N-terminal/Pyridine } \\
\text { nucleotide-disulfide oxidoreductase, class I }\end{array}$ \\
\hline NP_001045466.1 & ATP binding protein, putative, expressed & $\begin{array}{l}\text { Serine/threonine protein kinase/Leucine rich repeat, } \\
\text { N-terminal/Tyrosine protein kinase/ } \\
\text { Protein kinase, core/Leucine-rich repeat, } \\
\text { typical subtype }\end{array}$ \\
\hline NP_001045467.1 & Copine-4, putative, expressed & $\begin{array}{l}\text { Zinc finger, RING-type/Fungal lignin } \\
\text { peroxidase/Copine/von Willebrand factor, type A }\end{array}$ \\
\hline
\end{tabular}

Table 4 Wheat TCs and their predicted proteins

\begin{tabular}{|c|c|c|c|c|}
\hline Wheat TC & Protein & e-Value & $\begin{array}{l}\text { Length (No. of amino } \\
\text { acid residues) }\end{array}$ & $\begin{array}{l}\text { Identity } \\
(\%)\end{array}$ \\
\hline TC236864 & Unknown (Zea mays) & $9.0 \mathrm{e}-108$ & 166 & 95 \\
\hline TC236865 & Unknown (Zea mays) & $2.0 \mathrm{e}-88$ & 111 & 91 \\
\hline TC236866 & Unknown (Hordeum vulgare) & $2.0 \mathrm{e}-61$ & 67 & 86 \\
\hline TC236867 & $\begin{array}{l}\text { Integral membrane protein -2B } \\
\quad \text { (Taeniopygia guttata) }\end{array}$ & $0.0 \mathrm{e}+00$ & 224 & 97 \\
\hline TC237661 & Unknown (Hordeum vulgare) & $2.0 \mathrm{e}-69$ & 87 & 98 \\
\hline TC237663 & $\begin{array}{l}\text { Similar to ETS domain-containing protein } \\
\text { EIK-4 (Gallus gallus) }\end{array}$ & $4.0 \mathrm{e}-122$ & 166 & 98 \\
\hline TC238164 & Unknown (Oryza sativa japonica) & $1.0 \mathrm{e}-97$ & 199 & 80 \\
\hline TC238349 & Unknown (Oryza sativa japonica) & $9.0 \mathrm{e}-49$ & 50 & 92 \\
\hline TC238351 & Unknown (Zea mays) & $1.0 \mathrm{e}-63$ & 116 & 87 \\
\hline TC239719 & Protein coding (Danio rerio) & $0.0 \mathrm{e}+00$ & 522 & 99 \\
\hline TC244941 & Unknown (Oryza sativa japonica) & $5.0 \mathrm{e}-125$ & 207 & 91 \\
\hline TC244950 & Unknown (Oryza sativa japonica) & $3.0 \mathrm{e}-14$ & 54 & NS \\
\hline TC255809 & Unknown (Oryza sativa japonica) & $0.0 \mathrm{e}+00$ & 303 & 82 \\
\hline
\end{tabular}


$H 26$ is $1 \mathrm{cM}$ from the marker Xrwgs 12 derived from the wheat EST BE426418, and the AP003238 is the corresponding PAC of the wheat EST BE426418 in rice, these three genes could be candidate genes for resistance to Hessian fly. On the wheat side, one gene corresponding to TC237663 that was hit by the rice PAC AP003238, was found to have DNA-binding site (ETS domain) (Table 4). However, fine mapping as well as efforts toward cloning are needed to confirm these results.

Acknowledgments We thank Drs. Chao-Chien Jan and Bin Ye for critically reviewing the manuscript. This material is based upon work supported by the USDA-ARS CRIS Project No. 5442-22000-033-00D.

Open Access This article is distributed under the terms of the Creative Commons Attribution Noncommercial License which permits any noncommercial use, distribution, and reproduction in any medium, provided the original author(s) and source are credited.

\section{References}

Ahn S, Anderson JA, Sorrells ME, Tanksley SD (1993) Homoeologous relationships of rice, wheat and maize chromosomes. Mol Gen Genet 241:483-490

Altschul SF, Madden TL, Schaffer AA, Zhang J, Zhang Z, Miller W, Lipman DJ (1997) A new generation of protein database search programs. Nucleic Acids Res 25:3389-3402

Berzonsky WA, Ding H, Haley SD, Harris MO, Lamb RJ, Mckenzie RIH, Ohm HW, Patterson FL, Peairs F, Porter DR, Ratcliffe RH, Shanower TG (2003) Breeding wheat for resistance to insects. Plant Breed Rev 22:221-296

Bossolini E, Wicker T, Knobel PA, Keller B (2007) Comparison of orthologous loci from small grass genomes Brachypodium and rice: implications for wheat genomics and grass genome annotation. Plant J 49:704-717

Boyko EV, Gill KS, Mickelson-Young L, Nasuda S, Raupp WJ (1999) A high-density genetic linkage map of Aegilopes tauschii, the Dgenome progenitor of bread wheat. Theor Appl Genet 99:16-26

Cox TS, Hatchett JH (1994) Hessian fly resistance gene $H 26$ transferred from Triticum tauschii to common wheat. Crop Sci 34:958-960

Dellaporta SL, Wood J, Hicks JB (1983) A plant DNA minipreparation Version II. Plant Mol Biol Rep 1:19-21

Devos KM, Gale MD (1993) Extended genetic maps of the homoeologous group 3 chromosomes of wheat, rye, and barley. Theor Appl Genet 85:649-652

Dilbirligi M, Erayman M, Campbell BT, Randhawa HS, Baenziger PS, Dweikat I, Gill KS (2006) High-density mapping and comparative analysis of agronomically important traits on wheat chromosome 3A. Genomics 88:74-87

Distelfeld A, Uauy C, Olmos S, Schlatter A, Dubcovsky J, Fahima T (2004) Microcolinearity between a 2-cM region encompassing the grain protein content locus $G p c-6 B 1$ on wheat chromosome $6 \mathrm{~B}$ and a $350-\mathrm{kb}$ region on rice chromosome 2. Funct Integr Genom 4:59-66

Draper J, Mur LAJ, Jenkins G, Ghosh-Biswas GC, Bablak P, Hasterok R, Routledge APM (2001) Brachypodium dystachyon: a new model system for functional genomics in grasses. Plant Phys 127:1539-1555

Ellis J, Dodds P, Pryor T (2000) Structure, function and evolution of plant resistance genes. Curr Opin Plant Biol 3:278-284
Erayman M, Sandhu D, Sidhu D, Dilbirligi M, Baenziger PS, Gill KS (2004) Demarcating the gene-rich regions of the wheat genome. Nucl Acids Res 32:3546-3565

Foote T, Griffiths S, Allouis S, Moore G (2004) Construction and analysis of a BAC library in the grass Brachypodium sylvaticum and its use as a tool to bridge the gap between rice and wheat in elucidating gene content. Funct Integr Genomics 4:26-33

Formusoh ES, Hatchett JH, WC BlackIV, Stuart JJ (1996) Sex-linked inheritance of virulence against wheat resistance gene $H 9$ in the Hessian fly (Diptera: Cecidomyiidae). Ann Entomol Soc Am 89:428-434

Francki M, Carter M, Ryan K, Hunter A, Bellgard M, Appels R (2004) Comparative organization of wheat homoeologous group $3 \mathrm{~S}$ and $7 \mathrm{~L}$ using wheat-rice synteny and identification of potential markers for genes controlling xanthophyll content in wheat. Funct Integr Genomics 4:118-130

Gallun RL, Deay HO, Cartwright WB (1961) Four races of Hessian fly selected and developed from an Indiana population. Purdue University Agriculture Experiment Station Research Bulletin 732, West Lafayette, Indiana

Hammond-Kosack KE, Jones JDG (1997) Plant disease resistance genes. Annu Rev Plant Physiol Plant Mol Biol 48:575-607

Hasterok R, Marasek A, Donnison IS, Armstead I, Thomas A, King IP, Wolny E, Idziak D, Draper J, Jenkins G (2006) Alignment of the genomes of Brachypodium distachyon and temperate cereals and grasses using bacterial artificial chromosome landing with fluorescence in situ hybridization. Genetics 173:349-362

Huo N, Lazo G, Vogel J, Coleman-Derr D, Luo MC, Thilmony R, Garvin DF, Anderson OD, Gu Y-Q (2006) Construction and characterization of two BAC libraries from Brachypodium distachyon, a new model for grass genomics. Genome 49:1099-1108

Huo N, Lazo G, Vogel J, You FM, Ma Y, Hayden DM, Coleman-Derr D, Hill TA, Dvorak J, Anderson OD, Luo MC, Gu Y-Q (2008) The nuclear genome of Brachypodium distachyon: analysis of BAC end sequences. Funct Integr Genomics 8:135-147

Innis MA, Gelfand DH (1990) Optimization of PCR's. In: Innis MA, Gelfend DH, Sninsky JJ, White TJ (eds) PCR protocols: a guide to methods and applications. Academic Press, New York, pp 3-12

Koba T, Tsunewaki K (1978) Mapping of the $s$ and Ch2 genes on chromosome 3D of common wheat. Wheat Inform Serv 45-46:18-20

Kosambi DD (1944) The estimation of map distances from recombination values. Ann Eugen 12:172-175

Kudagamage CJ, Foster JE, Taylor PL, Chen BH (1990) Biotypes of the Hessian fly (Diptera: Cecidomyiidae) identified in the southeastern United States. J Entomol Sci 25:575-580

Kurata N, Moore G, Nagamura Y, Foote T, Yano M, Minobe Y, Gale $M$ (1994) Conservation of genomic structure between rice and wheat. Bio Technol 12:276-278

Lagudah ES, Moullet O, Appels R (1997) Map-based cloning of a gene sequence encoding a nucleotide-binding domain and a leucinerich region at the $\mathrm{Cre} 3$ nematode resistance locus of wheat. Genome 40:659-665

Lander E, Abrahamson J, Barlow A, Daly M, Lincoln S, Newburg L, Green P (1987) Mapmaker: a computer package for constructing genetic-linkage maps. Cytogenet Cell Genet 46:642

Li WL, Faris JD, Muthukrishnan S, Liu DJ, Chen PD, Gill BS (2001) Isolation and characterization of novel cDNA clones of acidic chitinase and $\beta$-1,3-glucanase from wheat spikes infected by Fusarium graminearum. Theor Appl Genet 102:353-362

Liu SX, Anderson JA (2003) Targeted molecular mapping of a major wheat QTL for Fusarium head blight resistance using wheat ESTs and synteny with rice. Genome 46:817-823

Liu XM, Brown-Guedira GL, Hatchett JH, Owuoche JO, Chen MS (2005) Genetic characterization and molecular mapping of a Hessian fly-resistance gene transferred from T. turgidum ssp. dicoccum to common wheat. Theor Appl Genet 111:1308-1315 
Ma ZQ, Gill BS, Sorrells ME, Tanksley SD (1993) RFLP markers linked to Hessian fly-resistance genes in wheat (Triticum aestivum L.) from Triticum tauschii (Coss.) Schmal. Theor Appl Genet 85:750-754

McIntosh RA, Yamazaki Y, Devos KM, Dubcovsky J, Rogers J, Appels R (2008) Catalogue of gene symbols for wheat. MacGene 2008. http://www.shigen.nig.ac.jp/wheat/komugi/genes/download. jsp. Acessed on 02 Jan 2009

Munkvold JD, Greene RA, Bermudez-Kandianis CE, La Rota CM, Edwards H, Sorrells SF, Dake T, Benscher D, Kantety R, Linkiewicz AM, Dubcovsky J, Akhunov ED, Dvořák J, Miftahudin GustafsonJP, Pathan MS, Nguyen HT, Matthews DE, Chao S, Lazo GR, Hummel DD, Anderson OD, Anderson JA, GonzalezHernandez JL, Peng JH, Lapitan N, Qi LL, Echalier B, Gill BS, Hossain KG, Kalavacharla V, Kianian SF, Sandhu D, Erayman M, Gill KS, McGuire PE, Qualset CO, Sorrells ME (2004) Group 3 chromosome bin maps of wheat and their relationship to rice chromosome 1. Genetics 168:639-650

Nelson JC, Van Deynze AE, Autrique E, Sorrells ME, Lu YH, Negre S, Bernard M, Leroy P (1995) Molecular mapping of wheat homoeologous group 3. Genome 38:525-533

Peng JH, Capitan NLV (2005) Characterization of EST-derived microsatellites in the wheat genome and development of eSSR markers. Funct Integr Genom 5:80-96

Perugini LD, Murphy JP, Marshall D, Brown-Guedira G (2008) Pm37, a new broadly effective powdery mildew resistance gene from Triticum timopheevii. Theor Appl Genet 116:417-425

Qi LL, Echalier B, Chao S, Lazo GR, Butler GE, Anderson OD, Akhunov ED, Dvorak J, Linkiewicz AM, Ratnasiri A, Dubcovsky J, Bermudez-Kandianis CE, Greene RA, Kantety R, La Rota CM, Munkvold JD, Sorrells SF, Sorrells ME, Dilbirligi M, Sidhu D, Erayman M, Randhawa HS, Sandhu D, Bondareva SN, Gill KS, Mahmoud AA, Ma XF, Miftahudin GustafsonJP, Conley EJ, Nduati V, Gonzalez-Hernandez JL, Anderson JA, Peng JH, Lapitan NL, Hossain KG, Kalavacharla V, Kianian SF, Pathan MS, Zhang DS, Nguyen HT, Choi DW, Fenton RD, Close TJ, McGuire PE, Qualset CO, Gill BS (2004) A chromosome bin map of 16,000 expressed sequence tag loci and distribution of genes among the three genomes of polyploid wheat. Genetics 168:701712

Ratcliffe RH, Hatchett JH (1997) Biology and genetics of the Hessian fly and resistance in wheat. In: Bondari K (ed) New developments in entomology. Research Signpost, Scientific Information Guild, Trivandram, India, pp 47-56

Ratcliffe RH, Safranski GG, Patterson FL, Ohm HW, Taylor PL (1994) Biotype status of Hessian fly (Diptera: Cecidomyiidae) populations from the eastern United States and their response to 14 Hessian fly resistance genes. J Econ Entomol 87:1113-1121
Röder MS, Korzun V, Wendehake K, Plaschke J, Tixier M, Leroy P, Ganal MW (1998) A microsatellite map of wheat. Genetics 149:2007-2023

Rozen S, Skaletsky HJ (2000) Primer3 on the WWW for general users and for biologist programmers. In: Akrawetz S, Misener S (eds) Bioinformatics methods and protocols: methods in molecular biology. Humana, Totawa, NJ, pp 365-386

Sardesai N, Nemacheck JA, Subramanyam S, Williams CE (2005) Identification and mapping of $H 32$, a new wheat gene conferring resistance to Hessian fly. Theor Appl Genet 111:1167-1173

Somers DJ, Isaac P, Edwards K (2004) A high-density microsatellite consensus map for bread wheat (Triticum aestivum L.). Theor Appl Genet 109:1105-1114

Sourdille P, Singh S, Cadalen T, Brown-Guedira GL, Gay G, Qi LL, Gill BS, Dufour P, Murigneux A, Bernard M (2004) Microsatellite-based deletion bin system for the establishment of geneticphysical map relationships in wheat (Triticum aestivum L.). Funct Integr Genomics 4:12-25

Vogel JP, Gu Y-Q, Twigg P, Lazo GR, Laudencia-Chingcuanco D, Hayden DM, Donze TJ, Vivian LA, Stamova B, Coleman-Derr D (2006) EST sequencing and phylogenetic analysis of the model grass Brachypodium distachyon. Theor Appl Genet 113:186-195

Wang T, Xu SS, Harris MO, Hu J, Liu L, Cai X (2006) Genetic characterization and molecular mapping of Hessian fly resistance genes derived from Aegilops tauschii in synthetic wheat. Theor Appl Genet 113:611-618

Ware DH, Jaiswal P, Ni J, Yap IV, Pan X, Clark KY, Teytelman L, Schmidt SC, Zhao W, Chang K, Cartinhour S, Stein LD, McCouch SR (2002) Gramene, a tool for grass genomics. Plant Physiol 130:1606-1613

Williams CE, Collier CC, Sardesai N, Ohm HW, Cambron SE (2003) Phenotypic assessment and mapped markers for $H 31$, a new wheat gene conferring resistance to Hessian fly (Diptera: Cecidomyiidae). Theor Appl Genet 107:1516-1523

Xu SS, Cai X, Wang T, Harris MO, Friesen TL (2006) Registration of two synthetic hexaploid wheat germplasms resistant to Hessian fly. Crop Sci 46:1401-1402

Yoshimura S, Yamanouchi U, Katayose Y, Toki S, Wang Z-X (1998) Expression of $\mathrm{Xal}$, a bacterial blight-resistance gene in rice, is induced by bacterial inoculation. Proc Natl Acad Sci USA 95:1663-1668

Zantoko L, Shukle RH (1997) Genetics of virulence in the Hessian fly to resistance gene H13 in wheat. J Hered 88:120-123

Zhang LY, Bernard M, Leroy P, Feuillet C, Sourdille P (2005) High transferability of bread wheat EST-derived SSRs to other cereals. Theor Appl Genet 111:677-687 